\title{
Study on Design, Fabrication and Properties of Biomedical Porous Titanium
}

\author{
Guangsheng Xu*, Huaixiao Luo, Zhanying Zhang, Liping Song and BingBing Yang \\ Department of Material Science and Engineering, China \\ *Corresponding author: Guangsheng Xu, Department of Material Science and Engineering, Xianyang, Shaanxi, China \\ Submission: 㭗January 31, 2018; Published: 阱 February 09, 2018
}

\section{Mini Review}

It has been shown that introducing porous structure in titanium and its alloys implant material is an effective way to reduce the "stress shielding" effect $[1,2]$. Interconnected pores in titanium and its alloys not only can decrease Young's modulus through tailoring porosity but also can enhance bone ingrowth and improve fixation $[3,4]$. Therefore, design, fabrication, mechanical behavior and biocompatibility of porous titanium and its alloys have become a research focus in this field. Development of fabrication methods, together with studies of mechanical behavior and biocompatibility is beneficial to improve the performance of porous titanium and its alloys for implant applications.

First, effect of pore size, pore shape, pore topology and strut material on mechanical properties of porous titanium and its alloys has been studied by using computer simulation methods. The results show that porosity increases as the pore size increases from $200 \mu \mathrm{m}$ to $500 \mu \mathrm{m}$, which also leads to the decrease in Young's modulus and yield strength of porous titanium. Porous titanium with square pores has a low Young's modulus and relatively high yield strength compared with the circle and hexagonal pores. Porous titanium has a good match of elastic modulus and high yield strength when pore topology is changed from regular array to staggered array. In addition, yield strength increases as the strut material changed from CP-Ti to Ti-6Al-4V alloy. Therefore, Young's modulus and yield stress of porous titanium and its alloys can be adjusted through designing pore size, pore shape, pore topological arrangement and strut material.

Based on the results of the above simulation, porous titanium is prepared by titanium mesh stacked-forced-sintering method (TMSS) [5]. Structure and mechanical properties of the prepared porous titanium are studied by tailoring pore structure parameters, strut material and process parameters [6,7]. The results show that porous titanium fabricated by TMSS has square pore structure. There are no cracks and inclusions on the strut. Mechanical behavior of porous titanium is anisotropic and sensitive to strain rate. The flow curves are smooth, stable and no obvious serration yield process. The strain for plastic platform region reaches up to $64 \%$. It can obtain a fine match of low elastic modulus and high yield strength by regulating the pore topology at the same porosity [8]. Porous titanium prepared by Ti-6Al-4V alloys owns Young's modulus and tensile strength in the range of 9.5 12.2GPa and 360 505 MPa, respectively. Fatigue fracture intensity level is about $40 \mathrm{MPa}$ at the testing condition of $\mathrm{R}=-1, \mathrm{f}=10 \mathrm{~Hz}$ and $\mathrm{N}=5 * 106$. Heat treatment has much more influence in the tensile stress but minor influence in the Young's modulus [9] (Figure 1).
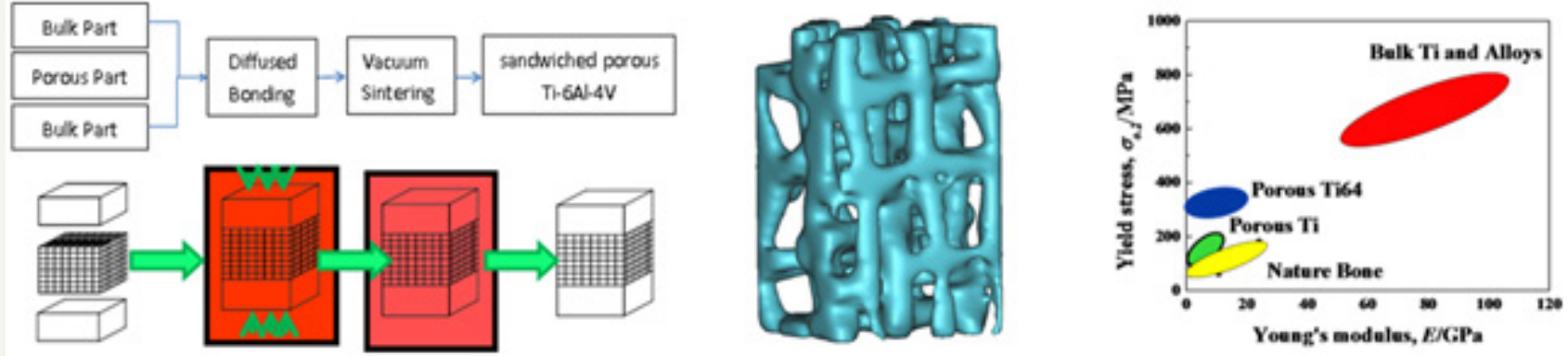

Figure 1a: Schematic diagram of porous titanium.

1b: Microstructure model of porous titanium,

1c: Mechanical properties of porous titanium, bulk titanium and natural bone. 


\section{References}

1. Long M, Rack HJ (1998) Titanium alloys in total joint replacement--a materials science perspective. Biomaterials 19(18): 1621-1639.

2. St-Pierre JP, Gauthier M, Lefebvre LP, Tabrizian M (2005)Threedimensional growth of differentiating MC3T3-E1 pre-osteoblasts on porous titanium scaffolds. Biomaterials 26(35): 7319-7328.

3. Takemoto M, Fujibayashi S, Neo M, Suzuki J, Kokubo T, et al. (2005) Mechanical properties and osteoconductivity of porous bioactive titanium. Biomaterials 26(30): 6014-6023.

4. Gepreel MA, Niinomi M (2013) Biocompatibility of Ti-alloys for longterm implantation. Journal of the Mechanical Behavior of Biomedical Materials 20: 407-415.
5. Xu GS (2013) The Chinese Journal of Nonferrous Metals 23(S1): 343.

6. Xu GS (2014) Rare Metal Materials and Engineering 43(11): 2778.

7. Li FP, Li J, Xu G, Liu G, Kou H, et al. Fabrication, pore structure and compressive behavior of anisotropic porous titanium for human trabecular bone implant applications. Journal of the Mechanical Behavior of Biomedical Materials 46: 104-114.

8. Xu GS, Kou HC, Liu XH, Li F, Li J, et a l. (2017) Microstructure and mechanical properties of porous titanium based on controlling young's modulus. Rare Metal Materials and Engineering 46(8): 2041-2048.

9. Xu GS (2017) Rare Metal Materials and Engineering 46(S1): 478.

\section{Your subsequent submission with Crimson Publishers will attain the below benefits}

- High-level peer review and editorial services

- Freely accessible online immediately upon publication

- Authors retain the copyright to their work

- Licensing it under a Creative Commons license

- Visibility through different online platforms

- Global attainment for your research

- Article availability in different formats (Pdf, E-pub, Full Text)

- Endless customer service

- Reasonable Membership services

- Reprints availability upon request

- One step article tracking system 